\title{
Navigating the Relational Psychic Economy of Disability: The Case of M
}

Accepted 30 July 2018 for publication in Psychoanalytic Dialogues

This article may not exactly replicate the final version published in the journal

\author{
Brian Watermeyer \\ Department of Rehabilitation Science, University of Cape Town, \\ brian.watermeyer@uct.ac.za, 0214066463
}

\section{Xanthe Hunt}

Department of Psychology, Stellenbosch University, xanthehuntwrites@gmail.com

\section{Leslie Swartz}

Department of Psychology, Stellenbosch University, xanthehuntwrites@gmail.com

\section{Poul Rohleder}

Department of Psychosocial and Psychoanalytic Studies, University of Essex, p.rohleder@essex.ac.uk

\section{Category}

Cultural Case Study

\section{Compliance with Ethical Standards}

\section{Disclosure of potential conflicts of interest}

The authors declare that the article signed by me meets quality standards and professional ethics and the original content is provided. We declare that the article is the results of the author's work, based on own research. We declare that the work has not been presented in this form in any other journal and has not been published or will be published in other journals.

The authors certify that they have NO affiliations with or involvement in any organization or entity with any financial interest (such as honoraria; educational grants; participation in speakers' bureaus; membership, employment, 
consultancies, stock ownership, or other equity interest; and expert testimony or patent-licensing arrangements), or non-financial interest (such as personal or professional relationships, affiliations, knowledge or beliefs) in the subject matter or materials discussed in this manuscript.

\section{Research involving human participants and/or animals}

All procedures performed in studies involving human participants were in accordance with the ethical standards of the institutional and/or national research committee and with the 1964 Helsinki declaration and its later amendments or comparable ethical standards.

\section{Informed consent}

Informed consent was obtained from all individual participants included in the study. 


\begin{abstract}
This paper presents a theoretically-informed psychosocial analysis of the case of $\mathrm{M}$, a physically disabled man from South Africa. We use M's account as a platform from which to consider projection, melancholic suspension and grief, as these are played out in the negotiation of dependency in relationships for disabled people. Making use of a case study methodology, we examine the various strategies through which M manages those disability stereotypes which are ascribed to him, creating a picture of how identity is negotiated in the face of interpersonal dependency as well as disablist prejudice. A central proposition is that, for M, upholding relationships which bring much-needed assistance means caring for the emotional lives of his carers, in a manner which leaves him more vulnerable to internalizing identity insults, and less able to resist his own oppression. Employing a psychoanalytic frame, we suggest that the 'melancholic suspension' which some disabled people may be subject to, may lead to the necessity to 'take on' certain projections, in the process of accessing muchneeded care. As shall be seen, $M$ maneuvers creatively through this relational realm by engaging in trade-offs between positive identity and physical need, employing strategies which include self-deprecation, the performance of mastery, playing with gender, and humor. With these and other techniques, he navigates the relational and psychic economy of his dependency.
\end{abstract}

\title{
Keywords
}

Disability, relational psychology, dependency, melancholic suspension 
Most of the world's disabled people ${ }^{1}$ (especially those in low- and middle-income countries) live with barriers to inclusion in all spheres of life, by dint of living in societies designed primarily for the nondisabled majority. Importantly for this discussion, disability exclusion often engenders dependency, as disabled people require assistance from others to compensate for inaccessible environments. Negotiating dependency in relationships will always present challenges, but may be particularly demanding for persons who have recently experienced a sudden onset of disability. Such adjustments are but one aspect of a raft of changes in social positioning described by people in these circumstances, who may suddenly be confronted with many previously unseen injustices, and experience exclusion where previously they typically may not have.

The onset of disability has traditionally been viewed by psychiatry as a process akin to bereavement, which requires the "working through" of grief related to loss of a bodily ideal (Thomas \& Siller, 1999). This position has, however, been strongly challenged by a host of voices from the global disability movement, and the discipline of disability studies. These writers make the point that it is structural discrimination, rather than bodily impairment, which is typically the primary cause of distress in the lives of disabled people (Swain, French, Barnes, \& Thomas, 2014). Consequently, according to this argument, grief experienced by this group may be primarily for the loss of a social status, rather than the corporeal reality of an impaired body.

Previously, Author (2016) made a case for applying the psychoanalytic notion of "melancholic suspension" (Cheng, 2000) to disability oppression (the concept was originally

\footnotetext{
${ }^{1}$ Among the international disability movement there are opposing views regarding appropriate language for referring to their constituency. This usage (disabled people, rather than persons with disabilities) is that preferred by proponents of the so-called social model of disability, which has its roots in the United Kingdom. Its implication is not that individuals are damaged, but rather, that they are people who have been "disabled" by an oppressive and excluding society.
} 
created as a tool for understanding the persistence of racial inequality). According to this view, race (and now disability) inequality is maintained in part by the disallowing of grief among oppressed groups. People in oppressed groups are defined negatively by the "distorted gaze" of the majority society (Akhtar, 2014, p. 138). People carrying a negatively valued identity (Black, disabled) are required to strive for attainment of an identity ideal (White, nondisabled), which is simultaneously foreclosed to them. This striving draws individuals away from an encounter with the self - a self which suffers loss at the hands of a hostile, often brutal society. Such an encounter may be a necessary precursor to the healing of selfidentity, and the personal power which can emanate from this.

This paper explores the psychosocial struggle of a physically disabled man whose predicament combines both situations - that is, he faces attacks on identity characteristic of melancholic suspension, while also being structurally and personally dependent on the very people who devalue him. One strategy for rebutting disability stereotypes about damage and inadequacy involves a wholesale disavowing of need, and assumption of a super-independent persona (Watermeyer, 2009; Watermeyer \& Swartz, 2008). But this is only possible if one possesses the necessary resources, such as financial support for personal assistance from the state. If not, there may be no choice but to accept help from wherever it comes, while engaging in a careful calculus regarding acceptance of, and resistance to, the denigrating assumptions which may come as part of the package.

In this paper, we draw on the story of $M$ to examine how identity is negotiated in the face of interpersonal dependency as well as disablist prejudice. A key proposition is that, for M, upholding relationships which bring much-needed assistance means caring for the emotional lives of his carers, in a manner which makes it harder for him to avoid internalizing identity insults, as well as confronting his own oppression. A critical psychoanalytic view of disablism (Watermeyer, 2012) holds that disabled people as a group 
are psychically exploited by the dominant majority, as containers for the projection of unwanted human characteristics such as shame and vulnerability. Within members of oppressed groups, we suggest that receptivity and resistance to such projections takes place at both conscious and unconscious levels, and stretches from a deliberate indulgence of the other, to being the unconscious victim of psychic scapegoating. As we shall see, $\mathrm{M}$ maneuvers creatively through this relational thicket by engaging in trade-offs between positive identity and physical need, employing strategies which include self-deprecation, the performance of mastery, playing with gender, and humor. With these and other techniques, he navigates the relational and psychic economy of his dependency.

\section{Case Study: Introducing M}

M was extensively interviewed by the second author as part of her doctoral research in the area of disability and sexuality. He was recruited through an advertisement distributed by a disability organization in the area, seeking participants for a larger study on disability and sexuality. M took part in two in-depth interviews exploring his identity and experience as a man with an acquired disability, and his relationships. The interviews followed a narrative interview approach, using photovoice (Wang \& Burris, 1997) as a method for eliciting narratives. Photovoice invites participants to create photographic images of things or moments that are symbolic of their experiences. These photographs are then brought to the interview to act as prompts for the exploration of personal narratives. In the first interview, much of M's narrative concerning his life centered on dependency, and negotiating nonsexual (as well as sexual) relationships. Topics covered included M's living and work environments at the prison where he was employed, his ways of relating to non-disabled and disabled others, and his experiences of disability in the context of his Black African Xhosa culture. He spoke of issues related to disability and identity that were interesting to pursue 
further as a psychosocial case study, and so he agreed to be interviewed a second time to follow up on issues he spoke about in the first interview. The interviews followed a mostly unstructured format, following the talk of M. In this respect the interview followed similar lines to Hollway and Jefferson's (2013) free association narrative interview. The taking of photographs acted as M's associations to the topic and led to the discussion of personal stories in the interviews. We do not present an analysis of the images themselves, but rather just the narratives elicited by them. In analyzing the interview transcripts, we adopt a psychoanalytic lens to interpreting the data and identifying themes related to the negotiation of identity and dependency. Our interpretations were made through discussion of the case material as a team. M gave his informed consent to participate in the study and interviews. We provide below a very general description of $\mathrm{M}$ so as to protect his anonymity.

A brief note must be made at this point about the role of the interviewer's position. Identity considerations are important in qualitative work. As an interviewer, the second author reflected carefully on the possible implications and biases of her subject position as a woman, someone without a visible disability, and a white South African, in relation to an interviewee who was a black African man living with a visible disability. Careful discussion between the authors led to an understanding that a range of identity differences between the interviewer and $\mathrm{M}$ appeared, on balance, to have been an advantage, allowing him to express his experience with a freedom born of recognising that the interviewer would not see the cultural significance of his behavior in a manner that a member of his own cultural community would, hence freeing him, to some extent at least, from the need to disguise his identity strategies.

Both similarities and differences between interviewer and participant can bring advantages and disadvantages. Too much similarity can bring the illusion of perfect understanding, in which details are seen as unnecessary, because we "know what this is 
about", impoverishing the emergent picture of the participant's unique experience.

Alternatively, a participant may feel that someone from a vastly different background just "couldn't get it"; but this seems not to have been the case here. The interviewer's impression was that M enjoyed the opportunity to freely describe his experience, without the fears he had at home in the Eastern Cape, where the cultural unacceptability of his positions was known by all.

\section{About M}

Now in his early forties, $M$ was born in the Eastern Cape Province of South Africa and, like many of his peers, moved to Cape Town after completing high school, where he found work as a warder in a large maximum-security prison. He felt that he did not have the disposition for the job, but retained it for the income, and took up residence with male colleagues in staff accommodation. In early 2011, M boarded a minibus taxi in the Eastern Cape, to begin the 1000-kilometer journey home after visiting his family. Two hours later the taxi collided with another vehicle, causing him injuries leading to paralysis in his lower body. The second author met $\mathrm{M}$ five-and-a-half years after the inauguration of his new life as a physically disabled man using a wheelchair for mobility.

Before returning to the case study of $\mathrm{M}$, we present some aspects of the theoretical framework that informed our interpretation of his narrative.

\section{Theoretical Background}

\section{The Structural Basis of Projection}

As noted above, societies which present myriad barriers to participation for disabled people engender relationships of dependency. In low- and middle-income countries, needs for care must often be accommodated informally, by family and friends, rather than paid 
employees, and this will carry implications for how identities coalesce around the evocative marker of disability. These were the circumstances in which $\mathrm{M}$ found himself.

For disabled people, a lack of wheelchair-accessible transport, or braille literature, or accessible toilet facilities, among many other examples, creates a situation where help must be asked for. Human dependency carries cultural associations of shame, help calls for gratitude and reciprocity, and identities and relationships are altered. Unequal access to an essential resource such as transportation creates power inequality - gaining the help one needs may involve personal compromises (Watermeyer \& Swartz, 2008). In a world replete with stereotypes about disabled people, gaining access to a needed resource may involve having to collude with prejudice, a reality which must have implications for socialization, and hence identity, in the lives of disabled people. How do disabled people navigate the forced dependencies of an inaccessible world? There may be no choice about dependency itself - the question is to do with what choices are made in how the dependency is framed, rationalized, digested and enacted.

Critical psychoanalytic thinkers on disability inequality (Marks, 1999; Watermeyer, 2012) argue that the impaired body evokes existential anxieties about frailty and mortality in the broader population, which are projected into the disabled community, cementing exclusion and prejudice. A common, pathologizing assumption is that the non-participation of disabled people in domains such as education, employment, politics and recreation is a consequence of intra-individual - that is, impairment-based - factors, rather than systemic injustice. Stereotypes of damage, tragedy, infantilization and invalidity are commonplace. For any oppressed minority, dealing with denigrating projections is an ever-present challenge, to which one may respond with rage, submission, or anything in between - the nature of both projections and responses holds influence for identity. But "disabling barriers" heighten one's vulnerability (Swain et al., 2014). Such barriers may be material in nature, but may also be 
attitudinal, prescribing conditions for inclusion in social groups. Of note is the question of which projections penetrate, or are allowed to penetrate, the self. Some will seep in unseen, and take up residence as assumptions about who one is, and what one's worth and abilities are. Others may be consciously tolerated as part of a psychic trade-off. Making sense of how unconscious defenses co-exist with conscious relational compromises is central to understanding identity positioning, as well as subjectivity.

Defenses such as projection and projective identification (Ogden, 1979) involve the disavowal of unwanted psychic material, such as vulnerability, shame or loss, which is (in the case of projection) attributed to others, or (in the case of projective identification), evacuated into others through unconscious processes of evocation. Part of the perpetuation of social inequality is the marking of people as available targets for unwanted feelings - living with oppression necessitates a constant confrontation with the ascriptions of others. The question of which psychic materials one takes in, either consciously or unwittingly, could be expressed as what one allows oneself to be made into by others. Disability, it has been argued, can threaten the psychic stability of the observer through its confounding and contradicting of social categories - it represents “matter out of place” (Douglas, 2003; Thomson, 1997), creating a fretfulness which demands the control of knowing. For example, we have cultural categories which make material dependency admissible under certain conditions, such as in infancy, old age, and patriarchal constructions of femininity. The imago of the physically impaired adult scrambles these prescriptions, rendering an experience of psychic "excess" (Butler, 1996) - an overflow, or "matter out of place" (Douglas, 1966) - which must be dealt with. As is the case for all oppressed minorities, it is thus the destiny of the disabled individual to constantly confront being defined from the outside (Kriegel, 1987). Perhaps observers, for their own psychic equilibrium, need to make a disabled adult male into a child, 
a woman, a hero, an invalid, a seer - these and many other unconsciously mediated, firmly held ascriptions are commonplace in the social lives of disabled people.

\section{Our Psychic Relationship to Dependency}

A common misconception, not least among mental health professionals, is that persons living with impairment suffer psychologically from "disability issues" - that is, emotional struggles emanating in essence from impairment of the body, which are peculiar to that group (Watermeyer, 2012). The attractiveness of this idea may lie in its bolstering of a reassuring myth of essential difference between disabled and nondisabled people. In one sense, disability is a harbinger of what will come to all of us, as our bodies age and fail, our senses cloud, we fall ill, and mortality becomes undeniable. As such, it is an outrage to the narcissism of late modernity, where we, self-adoring humans, persuade ourselves that money, technology, sophistication and medical science can save us. If images of disability threaten to topple this view, one strategic defense is to culturally construct disabled people as somehow inherently different to "us" (Žižek, 1992). In contrast, those disabled people who have "overcome" their disability (for example Paralympian athletes) are idealized as inspirational figures in order to reassure the narcissistic wishes of nondisabled people related to vulnerability and dependency.

The reality, as has been argued elsewhere (Watermeyer, 2009, 2012), is that disability does not "create" peculiar emotional conflicts, it merely strips back the material and relational resources which support defense mechanisms, exposing individuals to intimate encounters with testing, but universal, aspects of the human condition. Disabled or not, we all have a relationship with our own dependency, emerging from formative relationships in early life. All have had to somehow metabolize that layer of infantile dependency which was unmet, and the defensive strategies we used will shape our adult 
capacity for tolerating and making sense of dependency in ourselves and others. Donald Winnicott's theoretical picture of how early (or absolute) dependency is, at least in part, resolved into healthy, more separate object usage is an important backdrop here (Winnicott, 1958, 1965). Put simply, adequate early holding (Winnicott, 1965) is essential for separation, for self development, and hence for the processing of loss, allowing the psyche to move beyond melancholic states. Undigested echoes of absolute dependency, by contrast, present obstacles to separate relating, mature object usage, and grief. As will become clearer, these dynamics are of direct relevance to the predicament of melancholic suspension (Cheng, 2000), and to questions of the psychic implications of adult experiences of dependency. Because of all of the foregoing, depending physically or emotionally on others feels comfortable to some, but shamefully exposing and prohibited to others. Whatever the unconscious meanings of dependency are for the observer, it is these that are likely to become psychologically attached to disabled people, while being largely disavowed by a nondisabled majority. In truth, human dependency is universal, but bourgeois life is fitted out with bulwarks against its realization (Watermeyer \& Swartz, 2016). For those with the means, and with "normal" bodies, social organization is geared to provide experiences of control and mastery, distancing frailty and need. Developments in design, ranging from information technology to cars, promise ever greater convenience and desirability, soothing the mortality fears of their owners. By contrast, for a disabled person living in a society with poor access, this luxurious pretense is unworkable. Instead, struggles with taking up a dependent position in relationships must be confronted head-on, as life cannot continue any other way. Whatever the archaic meanings of dependency are in the inner lives of a disabled person, these must be encountered and integrated into one's sense of self.

The meaning which dependency takes in a relationship, therefore, is defined by three sets of elements. These are the unconscious and conscious meanings of dependency carried 
by first the helper, and then the helped, and the ways in which these interact in the recreation of object relationships which bind the participants together. For each, an intricate dance of othering and alliance, integration and disavowal, is taking place, as both hope to protect positive identity distinctiveness (Brewer, 1993). For the "dependent" one, negotiating and receiving assistance must somehow be factored into this equation. One conscious strategy involves the careful incorporation of the identity implications of dependency for the carer. Projective identification relies not only on contrasting the strong self with a weak other, but also on proximity. Being positioned as carer means being close to the dependency, but being defined as its counterpoint. What it means to care, who the carer needs to "become" while in that role, will carry strong elements of archaic repetition, a history transformed this way and that, in order to rescue a view of self as invulnerable. To some extent, allowing oneself to be cared for implies, consciously or otherwise, colluding in an archaic dance with the unconscious meanings of the other. This is the heart of projective identification, in which the projector's unconscious strategies awaken split off parts of self in the other which resonate with psychic materials which he or she needs to disavow, thus "preparing the way" for the unconscious psychic transaction to follow. Alternatively, care may be received in the context of a conscious and deliberate, albeit careful, indulging of the narcissistic fantasies of the other. For all of us, the caring role bolsters ego defenses, protecting us from all that it means - to us specifically - to be in need. Being cared for means taking part, knowingly or otherwise, in this protection.

Becoming disabled radically alters the experiences of social mirroring one is subject to (Watermeyer, 2012). In the words of one man living with tetraplegia, the onset of a severe impairment involves undergoing "a crash course in social inequality" (Gorgens, 2016, personal communication). One way of thinking about the psychic usefulness of the cars, cellphones and lifestyles of narcissistic modernity is to see these as selectively evoking and 
confirming parts of inner life which correlate with ideals of ability, security and wholeness. By contrast, persons with visible impairments typically face an unremitting stream of mirroring experiences which communicate negative imputations about ability, appearance, belonging, and much else. Where the "modern man" lives not only with material resources, but also with constant reassurances of his legitimacy, desirability and power, disabled persons must survive and achieve without these supports ((Watermeyer \& Swartz, 2016). Here, it is the vulnerable parts of inner life which are enlivened and confirmed by the world's messaging, and these must somehow be made a place for. Included here are the disabled person's own largely unconscious dependency meanings, shaped by the nature of defense mechanisms accumulated to deal with failures of care in infancy (Winnicott, 1963). As we have suggested above, unconscious enactment of these object relationships will occur to an extent inversely proportional to the body of unmet dependency needs which one has managed to grieve. As was outlined above, growing into separateness will inevitably involve loss, but that same loss builds psychic structure, as it incorporates an incremental internalization of the lost object, of the mother (Winnicott, 1953).

An interesting corollary of this is the likelihood that grief experiences following the onset of severe impairment involve, to some extent, the work of processing not only the new insult, but an inner store of pain surrounding dependency from which one was hitherto protected. A host of psychoanalytic theorists would agree that we all carry "malignant objects" (Klein, 1952), which may construe the shift in mirroring from reassurance to denigration, not as a sign of how one has changed, but a belated confirmation of the defective person one has been all along.

\section{Conscious Choices, Unconscious Subjects}


As should be clear, the extent to which one is conscious of - has insight into - one's conflicts regarding dependency, is crucial in determining how needing assistance from others impacts on identity. Young children are likely to make sense of experiences of abandonment through unconscious self-blame, rather than recognizing a parent's failings. Unless the experience is consciously grieved, the resultant shame will remain split off from consciousness, as a shadowy suspicion that one was inferior, and hence undeserving. In this split-off reality, the need for care is evidence of some intrinsic damage. For one in the helping role, this provides well for the projective identification of shame surrounding human need. For the person receiving assistance, assumptions will, via projective identification, insidiously seep right in, enlivening the self-denigrating meanings associated with early failures of care. In this way, power inequalities between helper and helped are cemented by an unconscious pact of domestication, and receiving assistance means a confirmation of shameful inferiority. The essence of the domestication here is that the helped has allowed him or herself to be used as a repository for the hated characteristics of the helper.

One may assume that if the person receiving assistance was aware of this transaction, he or she would immediately halt it. But disabled people living in societies ridden with barriers to participation have limited choices (Watermeyer \& Swartz, 2008). This may mean choosing to be consciously permissive with what others need to project.

\section{Returning to the Case of $M$}

Going back to the case of $\mathrm{M}$, let us consider his strategies and compromises as expressed in his story of adjusting to life as a disabled person in an inaccessible environment.

\section{Dependency and Identity}


I've struggled, because if you were born and you were active and now suddenly there's a change, so you need to accept first that there is this change now. There are so many things you think of, especially if you're alone...you're thinking, if I was still me I could have done this or could have done that...but I'm dependent now...I have to ask someone to assist me... I can do some stuff, but not like before. (M, speaking about his frustration at his functional limitations following the accident)

After a year of rehabilitation, $\mathrm{M}$ returned to work at the prison as an administrative officer. On his arrival, the buildings were not wheelchair accessible, and modifications were made to the block housing his office - the rest of the prison complex remained inaccessible. But besides physical barriers to inclusion, $\mathrm{M}$ was confronted with a social system functioning along hypermasculine lines, in which his capacity to fulfil the traditional attributes of manhood had been all but destroyed. Gaining both acceptance and the assistance he needed for performing everyday tasks required alterations to his public identity, as noted in the quote above.

After his return to the prison, $\mathrm{M}$ felt awkward, excluded and lonely. He described spending all of his time either in his room or office, moving between the two with as little interaction with others as possible. But he also needed help from his colleagues with tasks as intimate as washing and drying his clothes. This need for assistance was to mean a degree of calculated collusion with the meanings attached to his new state of dependence by his colleagues.

In Cheng's (2000) model of melancholic suspension, a lynchpin which holds oppressive relations in place is the disallowing of expressions of grief in subordinated persons (Cheng, 2000; Watermeyer, 2016) - that is, the enlivening of undigested absolute dependency (Winnicott, 1961) from early life. M was learning to live with layers of "social 
suffering" (Kleinman \& Kleinman, 1991) which seemed to be more about an altered social positioning and lack of access and formalized support, than about his functional limitations. Structural inequality in access to resources will always carry implications for interpersonal power.

In approaching how the onset of dependency can be psychically and intersubjectively negotiated, we propose a continuum of possibilities, which may be consciously or unconsciously manifested. At one extreme are psychological pathways characteristic of grieving. Processing grief, we suggest, requires the support of an accepting and understanding other who, amid the silences and prohibitions of devalued identities, may not be present. At the other extreme is the potential for internalizing the denigrating ascriptions which society now directs at one, negating both an entitlement to feelings of loss, and the possibility of political resistance.

\section{A Place for Grief}

So it was just that situation and that change of life now. You have to accept that you can't change it. It's changed already, so you have to deal with it and you have to live that life. Because you must tell yourself that you are not the only one; there are other people also in the same situation. (M, speaking about his grapple with his new body, and new identity)

Cheng's (2000) model of "melancholic suspension” describes how oppressive race relations in the United States are held in place by psychic prohibitions on racial grief among African Americans. In this framework, Black people face multi-level demands to strive towards a cultural ideal - that of Whiteness - while achievement of the ideal is, by definition, 
foreclosed $^{2}$ (Cheng, 2000). What this creates is an inner world of alienation from feelings about oneself and one's life, as attention and energy is focused on what "ought to be", rather than what is. Consequently, the losses inevitably associated with structural inequality and prejudice cannot be attended to and digested. Like an infant abandoned too early, this lack of holding precludes grief, trapping the individual in abjection for which there is no remedy.

How this creates melancholia, rather than allowing for mourning, should be clear. An implication of Cheng's (2000) view is that the "stuckness" of grief maintains inequality, and thus, that a process of grieving can reconfigure relationships. The model's applicability to disability inequality has been explored (Watermeyer, 2016). As noted above, "medicalizing" stereotypes view the lives of disabled people as steeped in losses to do with the body, tending to ignore those engendered by society. This focus on the body's "defects" forms the core of the melancholic predicament of disabled people, as it requires striving for an approximation of normalcy, while diverting attention from the ongoing losses associated with exclusion and prejudice (Author, 2016). As for the abandoned infant, the self-hatred of melancholia is the only sense-making available.

In M's story, we know that there is loss associated with his new experiences of exclusion and dependency, as well as the rupture in the way others see him. At the "grieving" end of the continuum, we suggest that if $\mathrm{M}$ is afforded the emotional support necessary for grieving to occur, this may have a protective effect for his self-identity. This occurs through promoting authentic compassion (within himself) for his circumstances, which diminishes the risk of internalization of stereotyping projections about disability. At the crux of such projections is an idea of inherent defect, analogous to the judgments of White supremacist

\footnotetext{
${ }^{2}$ Here, we draw on Cheng's racial terminology, as she intended it in her analyses. Whilst we acknowledge the limitations of such designations, we use them here in reference to her work and the meaning attached to these categories in her work.
} 
ideology, as well as to the abjection of the infant abandoned before any real internalization of the mother has taken place. In both cases, race and disability, the counterpoint to this essentialism, is an acknowledgment that the voice of loss is not to do with who one "is", but of the sufferings that social history has visited upon one. The more racial or disability minorities are able to contemplate their social suffering (Kleinman \& Kleinman, 1991), the less credible bigoted views become, and the less permeable psyches are to projections. This "grieving position" is reflected as follows in M's words:

You have to accept that you can't change it. It's changed already, so you have to deal with it and you have to live that life.

Expressed another way, one might say that "you need to accept that things have changed completely (on the outside) in order to reach recognition that, on the inside, things have not changed at all'. In Winnicott's (1961) terms, the loss of the tangible mother must be fully realized in order to allow for an experience of the internal mother. In this sense, we suggest, paradoxically, that grieving admitted for the ruptures and discontinuities of the social world will affirm a sense of continuity of identity in the internal world. Proceeding from here, if structural disadvantage stymies grieving, and this has implications for the health of self-identity, then that same structural disadvantage reduces one's ability to mediate what, in the form of projections, gets put into you, and what not. Not having processed his own losses will make it much harder - more psychologically dangerous - for M to consciously think about, and hence moderate, projections which incorporate loss stereotypes. As has been explicated elsewhere (Watermeyer, 2009), part of a life lived in the face of stereotyping involves attempts not at proving who one is, but at disproving who one is assumed to be. This is at the heart of the melancholic predicament - the imperative to strive for an identity which can never be attained, drawing one away from inhabiting one's 
own narrative in a manner which might bring loss to light and validation - here, the frozen watchfulness of an infant with an avoidant attachment comes to mind (Ainsworth, 1964). Grief is humanizing; its prohibition may dehumanize.

\section{Colluding Through Self-deprecation}

You must accept that you're going to be sharing jokes. You must joke and you must laugh. Then you must also be able to share jokes with them as well. Especially in my situation, I'm even making a joke or fun of myself so that they can feel comfortable to joke with me. And then you must not be sensitive about things and say, no, I can't talk like this to this man because of his situation. (M, speaking about the functioning of humor in his relationships with his colleagues at the prison)

If it is correct that visible disability evokes hidden anxieties in the observer, it should not surprise us that many disabled people find themselves filling reassuring roles in relationships. If one's appearance, one's presence, is unnerving to others, it is difficult to resist falling into an appeasing, caring role. This may be done through a simple sensitivity to others' needs and feelings, while putting one's own aside. But another way of reassuring is by consciously performing the projections one receives, in order to reify fantasies of intrinsic difference. With his self-deprecation, $\mathrm{M}$ seems to soothe the anxieties of his colleagues by reassuring them that they are, indeed, not like him at all. Instead, the projected characteristics are his and his alone. But it appears to us that M's self-ridiculing comes at a cost. Even when performed as a conscious strategy, it reinforces inequality, while constraining self-expression. Part of the melancholic predicament (Butler, 1996, 2003; Cheng, 2000; Author, 2016) is a narrowing of opportunities for exploring and elaborating feelings about one's social history. In its most familiar form, melancholia here is based on 
attempts at attaining an unreachable ideal, which draw one away from excavating one's own life, and the political mobilization which may emanate from this. But whether one is striving for an ideal or performing self-ridicule, the effect may be the same - that is, drawing one away from one's authentic, inner experience.

\section{Performing Mastery and Hope}

And now in order for me to move on with my life, I need now to accept myself first and be positive. Now I'm not going to let anyone talk negatively about me. Then I said, I'm going to show people that I'm still the same person, M, even though there are changes, but I'm still the same guy. (M, speaking about his desire to show his colleagues that disability need not make him impotent)

A further way in which $\mathrm{M}$ reassures his colleagues, thereby securing access to assistance, is by what may be described as the performance of mastery and hope. While his colleagues need him to confirm projections about his exclusive vulnerability, paradoxically they also require that he show robustness, good humor and optimism. Evidence of his vulnerability confirms prejudiced categories which may function to insulate observers from shame, but he must also show that he can stoically contain this ascription. This is because signs of distress in $\mathrm{M}$ will raise alarm about the sustainability of the projection. In short, he must prove that he is willing and able to psychically fill the role of scapegoat.

The persona $\mathrm{M}$ created after returning to his workplace as a disabled person required him to simultaneously be needy, vulnerable and grateful, yet also funny, reassuring and stoical. Within disability studies, this latter role has been conceptualized as the imperative to be "un-disabled" (Watermeyer, 2009, 2013), or as "compulsory able-bodiedness" (McRuer, 2010). One view sees the media phenomenon of the "supercrip" as an extreme instantiation 
of stoic reassurance. Here, disabled persons take on superhuman tasks, such as scaling mountains or swimming straits, purportedly in an effort to disprove denigrating stereotypes. If viewed as an instance of mimesis (Taussig, 1993) however, it may be argued that such attempts at sameness serve only to re-inscribe perceived difference. As in M's mixed persona described above, performing stoicism may function mainly to reaffirm the disabled person's capacity to withstand, and hence hold, projections. For Taussig (1993), at the heart of strivings for sameness is recognition of an ineluctable difference, which the striving itself only serves to reaffirm.

Some may view our interpretations in the previous two sections as a pessimistic overestimation of M's vulnerability, both to conscious domestication and pathological levels of unconscious projective identification. Of course, the limited exposure to $\mathrm{M}$ on which this paper is based allows only for an examination of possibilities, regarding his relational predicament, its possible intersubjective ramifications, and the relevance of these to a broader analysis of relationships surrounding disability-related dependency. In other words, we cannot with any confidence locate M's personality functioning in terms of key variables to do with his premorbid relationship with dependency, personal style of attachment, and so forth. We do not know what remnants of split-off, absolute dependency exist within him, awaiting enlivening confirmation by the manipulations of a disablist world. The interpretation we describe above may be viewed as on a continuum with other possibilities, notably that M's actions are, in part at least, the manifestations of healthy parts of self which seek, and have faith in, the possibility of a shared, intersubjective space between himself and his colleagues, which can allow sufficiently for everyone's needs regarding both intimacy and recognition. Put another way, the question of the quality of M's holding through the early navigation of transitional space (Winnicott, 1974) will have implications for his capacity to hold himself amid the transitions and cross-cutting needs of his new, adult milieu. To reiterate then, with 
this paper we aim only to outline the domain and parameters of possible dynamics surrounding dependency in the acutely unequal circumstances inhabited by most disabled people around the world.

\section{Playing with Gender}

You know, being a Xhosa man, you notice it when we are having cultural events...you know, we had this cultural event, then the men were talking, the men must talk. I was sitting in a wheelchair, and in our culture, out of respect, you can't talk while you are sitting, you have to stand up... and when it was my turn I thought, I used to stand up and talk as a man, now I can't... and when we drink the African beer, someone has to come and hold it for me... and I felt like, no, in my culture I'm not man enough. (M, speaking about the cultural dimensions of his experience of being in a wheelchair)

Here, $M$ explained that as a disabled person he felt incompetent, unable and excluded. M's cultural home is a Xhosa community in the Eastern Cape, to which he returns from time to time. Traditionally, this is a patriarchal culture, in which men are required to eschew vulnerability.

In his community of origin, $\mathrm{M}$ felt no option but attempting, and failing, to be a stereotypical Xhosa man. Perhaps surprisingly, the equally hypermasculine environment of the prison offered other options. Using his charm and willingness to be teased as tokens, $\mathrm{M}$ began to display characteristics of stereotypical femininity at the prison. This meant assuming an openly dependent persona, even against the hypermasculine culture of prison warders. Paradoxically, $\mathrm{M}$ found that he could be admitted to the male "pack" by feminizing himself. It appeared that this was more tolerable to him than the total emasculation and exclusion he experienced in his home village. 
There are problems, of course, with evidence in a study such as this where we are retrospectively working from an individual's narrative about something as slippery as gender identity. However, led by the centrality of shifting definitions of masculinity in M's narrative, it seems clear that there was a distinct change in his gender identification which happened in the course of his transition to a disabled identity.

There is much more to be said about gender in M's narrative, which can shed light on the complex relationship between gender - in particular femininity - and disability (Inahara, 2009). This will be dealt with in detail in a forthcoming publication by the authors. But what remains to be said here is that M's assumption of a feminized gender position at the prison was not a neutral or uncalculated move. If we consider queering as a reaction to projection, we are able to see how M's "taking on" of feminizing ascriptions allows him to attain resources which he needs. It is worth briefly drawing attention to the overlap between disability studies as a discipline, and queer theory, and the implications of this overlap for thinking about queering in relation to disability in the present psychoanalytic work.

As Sherry (2004) notes, "Disabled people have many shared experiences with queer people, as do their respective academic disciplines. Both Disability Studies and Queer Theory problematize the public and the private, the social and the biological, difference, stigma and deviance, and the construction of identities. Both challenge universalizing norms that marginalize those who don't conform to hegemonic normalcy (p. 769)".

At the heart of Queer theory is opposition to hegemonic normalcy (Tremain, 2000). In relation to the present work, queer theory clearly has relevance. Butler's seminal texts, Gender trouble (1990) and Bodies that matter (1993), are concerned with a specific aspect of this relevance: performativity. Performativity is not "a singular or deliberate act", but is instead - "a reiterative and citational practice by which discourse produces the effects that it names" (1993, p. 2). This may seem opaque. But, in the present context, is one example of 
the manner in which queering can contribute to thinking through M's negotiation of disability.

The playfulness of queering lies in the fact that, by assuming a dependent position amongst the men, he is able to - consciously or unconsciously - put the men to work doing feminine tasks for him - caring for him.

As he explains:

I've got a washing machine, but they said, no, come, put the washing there. I can't remember when last I was in the laundry loading my washing. I can't remember when, because they are always there for it. The guys are always there for it.

\section{Deploying Humor}

Finally, in all of this, $\mathrm{M}$ shows how humor can be used to support relationships which would otherwise falter under the weight of his needs, both real and imagined. M's humor seemed to provide permission to his colleagues to position his identity as they wished, or needed, to. His willingness to be joked about communicated, on the one hand, that he was receptive to projections, while, on the other hand, at times gave him opportunities for mischievous table-turning. In the first sense, M's funniness gave to others a mechanism for making sense of an otherwise undigestible reality - that of one man assisting another with personal care.

Recounting how he first began to break the ice with the men in the prison hostel, his narrative centered on his capacity to make the men feel comfortable with him. Many of the jokes they shared, he noted, took on a sexual tone. He said that he did not mind.

Finding himself in a bar with his friends, they were approached by a group of women. Immediately, the men began chastising him for looking at the potentially eligible ladies: 
The guys said to me, hey, don't even look, you can't do anything, man. Don't waste these ladies. They said, no, man, don't waste their time, let us try our luck here.

When M's girlfriend became pregnant, the men questioned him endlessly:

They kept teasing, "Are you sure this is your baby? Maybe someone made this baby for you". You must be able to laugh so that they can also laugh with you. Comfortable. If you make them comfortable, then you will see you have friends. If they are not comfortable with you, no one is going to surround you.

Besides making his colleagues comfortable, M may also have been showing evidence of a yearning for, and invitation to, robust and authentic relating. Such honesty and realness in interactions is described by many people with visible impairments as painfully rare (Watermeyer, 2013; Watermeyer \& Swartz, 2008). M may be asking for this, but at the same time is reassuring others that he is strong enough to withstand their projections - an openness to relationship means vulnerability to exploitation.

\section{Conclusion}

The crux of our argument is the quite simple proposition that material dependency constricts space for experiencing, understanding and expressing emotion, in both intrapsychic and interpersonal domains. For disabled people such as M, this lack of space can make attainment of an authentic position of, say, rightful indignation at social injustice very difficult. Maneuvers such as deliberate collusion and queering may be viewed as creative responses to the melancholic predicament, but remain operational only within its bounds.

In Violence, mourning, politics, Judith Butler (2003) describes a state of psychosocial precarity which involves being vulnerable to exploitation due to a lack of 
security (Butler, 2003; Neilson \& Rossiter, 2005; Standing, 2016). Precarity suggests the potential for, but not the presence of, violability and harm. In the case of $\mathrm{M}$, we see that in the face of projections, he inhabits a psychological space characterized by just such a precarity: as constantly as he is subjected to the projections of others, must he joust with, dance with, or otherwise entertain or elude these projections. This limits his psychological living space.

Residing in such a state can preclude grief. In M's narrative, we see an existential state characterized by a certain inner immediacy, a lack of past and future, based on the necessity to manage the reactions of the world "out there" rather than the world "in here". What we observed in $\mathrm{M}$, as he negotiated material and relational checks and balances, could be described as an emotional "living hand to mouth".

Although M maneuvers creatively through this relational realm, its dynamics remain weighted against him. Space for feeling and expressing grief, and otherwise living with congruity in his social system would reduce this precarity, but cultural associations with disability make this unlikely. An essential ingredient in shifting constraints on the public emotional lives of disabled people is structural change in access to the means of social participation. Structural and economic barriers delimit opportunities for elaborating one's identity, giving affordances to the privileged. One such affordance may be the security (fiscal, emotional) required to consciously admit grief, and have it attended to with care.

\section{References}

Ainsworth, M. D. (1964). Patterns of attachment behavior shown by the infant in interaction with his mother. Merrill-Palmer Quarterly of Behavior and Development, 10, 51-58. Akhtar, S. (2014). The mental pain of minorities. British Journal of Psychotherapy, 30(2), $136-153$. 
Brewer, M. B. (1993). Social identity, distinctiveness, and in-group homogeneity. Social Cognition, 11(1), 150-164.

Butler, J. (1993). Bodies that matter: On the discursive limits of "sex". New York \& London: Routledge.

Butler, J. (1996). Imitation and gender insubordination. In A. Garry \& M. Pearsall (Eds.), Women, knowledge, and reality: Explorations in feminist philosophy (2nd ed., pp. 371-387). New York: Routledge.

Butler, J. (2003). Violence, mourning, politics. Studies in Gender and Sexuality, 4(1), 9-37.

Cheng, A. A. (2000). The melancholy of race: Psychoanalysis, assimilation, and hidden grief. Oxford University Press.

Douglas, M. (1966). Purity and danger: An analysis of concepts of pollution and taboo. London: Routledge.

Douglas, M. (2003). Purity and danger: An analysis of concepts of pollution and taboo. Routledge.

Hollway, W., \& Jefferson, T. (2013). Doing qualitative research differently: A psychosocial approach (2nd ed.). London: Sage Publications.

Inahara, M. (2009). This body which is not one: The body, femininity and disability. Body \& Society, 15(1), 47-62.

Klein, M. (1952). Some theoretical conclusions regarding the emotional life of the infant. Austria: Hogarth Press and the Institute of Psycho-Analysis.

Kleinman, A., \& Kleinman, J. (1991). Suffering and its professional transformation: Toward an ethnography of interpersonal experience. Culture, Medicine and Psychiatry, 15(3), 275.

Kriegel, L. (1987). The cripple in literature. In A.G.T. Joe (Ed.), Images of the disabled, disabling images. New York: Praeger. 
Marks, D. (1999). Disability: Controversial debates and psychosocial perspectives. Psychology Press.

McRuer, R. (2010). Compulsory able-bodiedness and queer/disabled existence. The Disability Studies Reader, 3, 383-392.

Neilson, B., \& Rossiter, N. (2005). From precarity to precariousness and back again: Labour, life and unstable networks. Fibreculture, 5, 022.

Ogden, T. H. (1979). On projective identification. The International Journal of PsychoAnalysis, 60, 357.

Sherry, M. (2004). Overlaps and contradictions between queer theory and disability studies. Disability \& Society, 19(7), 769-783.

Standing, G. (2016). The precariat: The new dangerous class. Bloomsbury Publishing.

Swain, J., French, S., Barnes, C., \& Thomas, C. (Eds.). Disabling barriers - Enabling environments. Los Angeles: SAGE.

Taussig, M. T. (1993). Mimesis and alterity: A particular history of the senses. Psychology Press.

Thomas, K. R., \& Siller, J. (1999). Object loss, mourning, and adjustment to disability. Psychoanalytic Psychology, 16(2), 179.

Thomson, R. G. (1997). Extraordinary bodies: Figuring physical disability in American culture and literature. Columbia University Press.

Tremain, S. (2000). Queering disabled sexuality studies. Sexuality and Disability, 18(4), 291299.

Wang, C., \& Burris, M. (1997). Photovoice: Concept, methodology, and use for participatory needs assessment. Health Education \& Behavior, 24, 369-387.

Watermeyer, B. (2009). Claiming loss in disability. Disability and Society, 24(1), 91-102. 
Watermeyer, B. (2012). Is it possible to create a politically engaged, contextual psychology of disability? Disability \& Society, 27 (2), 161-174.

Watermeyer, B. (2013). Towards a contextual psychology of disablism. London: Routledge.

Watermeyer, B. (2016). 'I Don’t Have Time for an Emotional Life': Marginalization, dependency and melancholic suspension in disability. Culture, Medicine, and Psychiatry, 41 (1), 142-160.

Watermeyer, B. \& Swartz, L. (2008). Conceptualising the psycho-emotional aspects of disability and impairment: The distortion of personal and psychic boundaries. Disability and Society, 23(6), 599-610.

Watermeyer, B. \& Swartz, L. (2016). Disablism, Identity and Self: Discrimination as a traumatic assault on subjectivity. Journal of Community \& Applied Social Psychology, 26(3), 268-276

Winnicott, D. (1953). Transitional objects and transitional phenomena. International Journal of Psychoanalysis, 34, 89-97.

Winnicott, D. (1958). Collected papers: Through paediatrics to psychoanalysis. London: Tavistock.

Winnicott, D. W. (1961). The effect of psychotic parents on the emotional development of the child. British Journal of Psychiatric Social Work, 6(1), 13-20.

Winnicott, D. W. (1963). Dependence in infant care, in child care, and in the psycho-analytic setting. The International Journal of Psycho-Analysis, 44, 339.

Winnicott, D. (1965). The family and individual development. London: Tavistock.

Winnicott, D. W. (1974). Fear of breakdown. International Review of Psycho-Analysis, 1, $103-107$.

Žižek, S. (1992). Looking awry: An introduction to Jacques Lacan through popular culture. MIT Press. 